\title{
THE SPECIFICS OF OCULAR PROSTHETICS IN PATIENTS WITH DIABETES MELLITUS
}

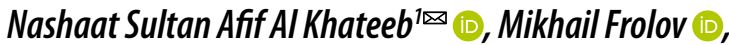 Viktor Shklyaruk ${ }^{1,2}$ (1)}

\author{
${ }^{1}$ Peoples Friendship University of Russia, Moscow, Russia \\ ${ }^{2}$ Center of Ocular Prosthetics, Moscow

\section{insa_109@yahoo.com}

ABSTRACT - Aim. To study the effect of $\mathrm{pH}$ on the conjunctival cavity.

Materials and methods. All patients underwent the following studies: Biomicroscopy of the conjunctival cavity, evaluation of the cosmetic effect of prosthetics, sensation and comfort, and bacterial culture of the discharge.

The results of the study. As a result of the study, it was found that patients using ocular prostheses with concomitant diabetes mellitus have a $\mathrm{pH}$ shift in the conjunctival cavity to the alkaline side, which will lead to partial inflammatory reactions of the conjunctival cavity, resulting in a decrease in the desired cosmetic effect

Conclusion. Diabetic patients require a lot of attention and a more thorough approach to meeting the conditions for normalizing the $\mathrm{pH}$ of the conjunctival cavity, and the terms of replacing the prosthesis, as a result, achieving a good cosmetic effect.

KEYW ORDS - ocular prosthetics, anophthalmia, diabetes mellitus.

\section{INTRODUCTION}

Every year in Russia, from 7.5 to 8 thousand enucleations are performed, according to the Ministry of Health of the Russian Federation from 1999.

More than 450,000 patients in the Russian Federation need eye prosthetics, while the prevalence of anophthalmus reaches 24.47 per 10,000 population (Lavrentieva, 2013; Federal clinical guidelines, 2015).

The only method of medical and social rehabilitation of people with anophthalmus, to date, remains eye prosthetics (Perfilieva et al.,2014; Perfilieva et al.,2015, p. 120).

Cosmetic and functional cosmetic results of ocular prosthetics depend on a combination of factors such as compliance with patient hygiene rules and timely replacement of prostheses(Perfilieva et al.,2014; Perfilieva et al.,2015, p. 120).

Diabetes affects five percent of the world's population. Another twenty-five percent are carriers of the disease. The significance of this disease in the world is growing, according to forecasts, by 2030, diabetes will become the seventh leading cause of death in the world(Roglic et al.,2005, p. 2130).

\section{MATERIALS AND METHODS}

The work is carried out at the Department of Ophthalmology of the RUDN University and at the Center for Eye Prosthetics of Moscow from September 2018 to the present.

Under our supervision, there were 100 patients aged 8 to 82 years. Patients were divided into two groups: the first group (control group) - patients with anophthalmus and without diabetes mellitus (50 people; $100 \%$ ), the second group (study group) patients with anophthalmus complicated by diabetes mellitus (50 people; $100 \%$,). All patients underwent the following studies: Biomicroscopy of the conjunctival cavity, evaluation of the cosmetic effect of prosthetics, sensation and comfort, and bacterial culture of the discharge. The material was processed statistically using computer programs based on the Excel.

\section{RESULTS}

The results of our study when studying the condition of the acid-base balance of the conjunctival cavity showed: in the control group - 37 patients (37 eyes, $74 \%$ ) the $\mathrm{pH}$ is $7.0-7.5$, in 13 patients ( 13 eyes, $26 \%$ ) the $\mathrm{pH}$ is $8,0-8.5$, and in the second study group in 8 patients ( 8 eyes, $16 \%$ ), the $\mathrm{pH}$ is $8.0-8.5$, in 23 patients (23 eyes, $46 \%$ ), the $\mathrm{pH}$ is $9.0-9,5$, in 19 patients (19 eyes, $38 \%$ ), the $\mathrm{pH}$ is $10.0-11$. (Table 1 ).

Table 1. pH Measurement of the conjunctival cavity

\begin{tabular}{l|l|l|l|l|l}
\hline \multirow{2}{*}{ № } & \multirow{2}{*}{ Patientgroups, $\mathrm{n}, \%$} & \multicolumn{4}{|l}{$\mathrm{PH}$} \\
\cline { 3 - 6 } & & $7-7,5$ & $8-8,5$ & $9-9,5$ & $10-11$ \\
\hline 1 & $1^{\text {st }}$ group, $\mathrm{n}=50(100 \%)$ & $37(74 \%)$ & $13(26 \%)$ & - & - \\
\hline 2 & $2^{\text {nd }}$ group, $\mathrm{n}=50(100 \%)$ & - & $8(16 \%)$ & $23(46 \%)$ & $19(38 \%)$ \\
\hline
\end{tabular}

In the study group, frequent inflammatory processes in the conjunctival cavity were noted, and staphylococcus aureus was found during bacterial culture that urgent treatment was required urgent treatment especially in those patients with high $\mathrm{PH}$, while in the control group patients did not show frequent inflammatory reactions. In $90 \%$ of the control group, the bacterial culture was sterile (Fig. 1). 


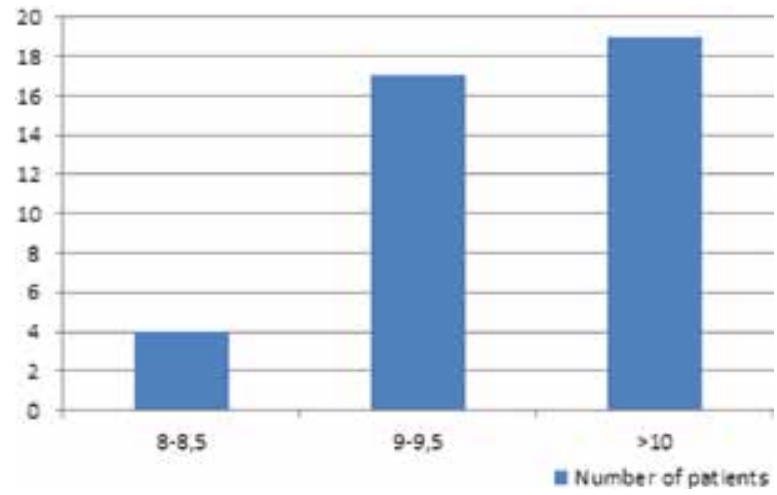

Fig. 1. The frequency of inflammatory reactions in patients with diabetes, depending on the $\mathrm{pH}$ of the connective cavity

Patients using ocular prostheses with a concomitant disease with diabetes mellitus, which comply with the terms of replacement of the ocular prosthesis (1 year for a glass prosthesis and two years for a plastic prosthesis), have less inflammatory reactions in the conjunctival cavity and a better cosmetic effect, but worse than in patients without diabetes.

\section{DISCUSSION}

On the territory of the Russian Federation, more than 450,000 patients require ocular prosthetics (Lavrentieva, 2013; Federal clinical guidelines, 2015), among them there are patients with diabetes mellitus, who have their own characteristics that affect the results of ocular prosthetics, and therefore, the problem of ocular prosthetics in patients with concomitant diabetes is relevant and requires special attention. In patients using ocular prostheses, the $\mathrm{pH}$ of the conjunctival cavity is normal or shifted to the alkaline side, among them patients with diabetes mellitus whose $\mathrm{pH}$ is shifted not only to the weak, but also to the more aggressive alkaline side, which leads to frequent inflammatory reactions in the conjunctival cavity and the appearance of Staphylococcus aureus, which requires immediate treatment, and frequent inflammatory reactions of the conjunctival cavity in these patients leads to a decrease in the desired cosmetic effect obtained from ocular prosthetics, therefore, normalization of the $\mathrm{pH}$ of the conjunctival cavity and timely replacement of the ocular prosthesis are some of the important conditions for preventing inflammatory reactions of the conjunctival cavity and obtaining the desired cosmetic effect from ocular prosthetics.

\section{REFERENCES}

Federal clinical guidelines. Enucleation, evisceration: indications, surgical technique, rehabilitation. (2015).

LAVRentieva, N. V. (2013). Medical rehabilitation with anophthalmus and analysis of the state of ocular prosthetics in the territory of the Russian Federation. Candidate of Medical Science, 151.

Perfilieva, E. A.,Frolov, M. A.,\&Shklyaruk, V. V. (2014). The effectiveness of ocular prosthetics. Poster report "Actual Issues of Ophthalmology-2014". MNTK Eye Microsurgery named after S.N. Fedorova.

Perfilieva, E. A.,Frolov, M. A.,\&Shklyaruk, V. V. (2015). Features of eye prosthetics in childhood. Ophthalmology: results and prospects, 120-121.

Roglic, G., Unwin, N., Bennett, P.H., Mathers, C., Tuomilehto, J., Nag, S., Connolly, V.,\& King, $\mathrm{H}$. The Burden of Mortality Attributable to Diabetes. Realistic estimates for the year 2000. Diabetes Care 2005, 28 (9), 2130-2135. 